Revista de Derecho

Universidad Católica del Norte

Sección: Estudios

Ańo 17 - No 2, 2010

pp. $21-52$

\title{
EL SUMINISTRO DE INFORMACIÓN COMO TÉCNICA DE PROTECCIÓN DE LOS CONSUMIDORES: LOS DEBERES PRECONTRACTUALES DE INFORMACIÓN*
}

\author{
IŃIGO DE LA MAZA GAZMURI**
}

RESUMEN: En el ámbito nacional como en el comparado, existe acuerdo respecto a la necesidad de proteger jurídicamente a los consumidores en sus relaciones con los proveedores. Una cuestión diversa de la anterior -pero cercanamente relacionada- consiste en determinar cómo proteger a los consumidores. En torno a esta última interrogante se endereza este trabajo. Sabemos que existe una relación suficientemente evidente entre las razones que justifican la protección de los consumidores y las técnicas a que se recurra para hacerlo. Por lo tanto, una percepción más agudizada acerca del por qué proteger a los consumidores debería contribuir a agudizar nuestra comprensión acerca de cómo hacerlo.

Respecto de la primera pregunta, señalaré que la razón se encuentra en una desigualdad en la posición negocial que suele caracterizar la situación de los consumidores y proveedores en las relaciones de consumo. Dicha desigualdad, en una parte muy relevante, se explica por la presencia de asimetrías informativas. Una de las técnicas más frecuentes para nivelar la desigualdad entre proveedores y consumidores es el suministro de información a los consumidores, que nos entrega la respuesta a cómo protegerlos. Para ello, advertiré que existen diversas formas de proveerla y centraré mi atención en aquellas que se imponen sobre los privados, para luego examinar la regla general de deberes precontractuales de información en la ley No 19.496 sobre protección de los consumidores.

PALABRAS CLAVE: Protección a los consumidores - información - relación pre contractual - derechos de los consumidores.

\footnotetext{
* Este artículo se enmarca en el Proyecto FONDECYT Regular No 1100029 sobre los deberes precontractuales de información en el Derecho chileno.

** Abogado, Doctor en Derecho, Profesor de Derecho Civil de la Facultad de Derecho de la Universidad Diego Portales (CHILE). Correo electrónico: inigo.delamaza@udp.cl

Fecha de recepción: 13 de septiembre de 2010.

Fecha de aceptación: 5 de noviembre de 2010.
} 


\title{
THE SUPPLY OF INFORMATION AS A TECHNIQUE OF Protection to THE CONSUMERS: Pre-CONTRACTUAL DUTIES OF INFORMATION
}

\begin{abstract}
In the national sphere as well as in the comparative, there is agreement regarding the need to legally protect the consumers as far as the suppliers. A different topic -but closely related-consists in determining how to protect the consumers. This work deals with this last question. We know there is a relationship close enough among the reasons that justify the protection to the consumers and the techniques resorted to achieve this. Thus, a more acute perception towards why to protect the consumers should contribute to our comprehension of how to accomplish it.

Regarding the first question, I will indicate that the reason lies upon the inequality in the negotiating position that usually characterizes the situation of consumers as opposed to that of the supplier. Said inequality is explained by the presence of informative asymmetries. One of the techniques most frequently used to level the disparity among suppliers and consumers is providing information to the consumers. This gives us an insight on how to protect them. For this purpose I will note that there are diverse forms to provide it and I shall focus my attention in those that are over the private sector to then examine the general rule of precontractual duties of information in law No 19,496 about protection to the consumers.
\end{abstract}

KEY WORDS: Protection to consumers - information - pre-contractual relationship - consumer rights.

\section{INTRODUCCIÓN}

En general, tanto en el ámbito nacional como en el comparado, existe acuerdo respecto a la necesidad de proteger jurídicamente a los consumidores en sus relaciones con proveedores. Una cuestión diversa de la anterior -pero cercanamente relacionada- consiste en determinar cómo proteger a los consumidores. En torno a esta última interrogante se endereza este trabajo.

Mi primera sugerencia es que existe una relación suficientemente evidente entre las razones que justifican la protección de los consumidores y las técnicas a que se recurra para hacerlo. Por lo tanto, una percepción más agudizada acerca del por qué proteger a los consumidores debería contribuir a agudizar nuestra comprensión acerca de cómo hacerlo.

Respecto de la pregunta acerca de por qué proteger a los consumidores, señalaré que la razón se encuentra en una desigualdad en la posición 
negocial que suele caracterizar la posición de consumidores y proveedores en las relaciones de consumo. Dicha desigualdad, en una parte muy relevante, se explica por la presencia de asimetrías informativas.

La información es el antídoto de la ignorancia, por lo mismo, si el problema se encuentra en la falta de información de los consumidores, entonces el remedio es, precisamente, la información. De ahí fluye, con toda naturalidad, que una de las técnicas más frecuentes para nivelar la desigualdad entre proveedores y consumidores sea el suministro de información a los consumidores. Ese es el cómo.

Respecto del suministro de información advertiré que existen diversas formas de proveerla y centraré mi atención en aquellas que se imponen sobre los privados. A continuación diré algunas palabras sobre las ventajas y limitaciones de la imposición del suministro de información como técnica de protección de los consumidores, con eso concluyo la primera parte de este trabajo.

Dedico la segunda parte a examinar la regla general de deberes precontractuales de información en la ley No 19.496 sobre protección de los consumidores (en adelante, ley 19.496). En particular, examinaré el artículo 3 b) de dicha ley, explicando por qué es posible afirmar que se trata de una norma general sobre deberes precontractuales de informar, dando alguna noticia acerca de sus principales características y, finalmente, deteniéndome sobre las consecuencias de su incumplimiento.

\section{1) LA PROTECCIÓN DE LOS CONSUMIDORES: JUSTIFICACIÓN Y TÉCNICAS ${ }^{1}$}

\section{1) ¿POR QUÉ?}

Existen, al menos, dos lugares comunes en la literatura jurídica sobre relaciones de consumo. El primero de ellos es la necesidad de proteger jurídicamente a los consumidores en sus relaciones con proveedores. El segundo lugar común es que la razón que justifica dicha protección -más bien extraña al derecho común de los contratos- es la desigualdad que existe entre quien provee un bien o servicio y quien accede a él en calidad de consumidor ${ }^{2}$.

\footnotetext{
1 Esta primera parte se nutre generosamente de De la Maza Gazmuri, I. (2010). Los límites del deber precontractual de información, Cizur Menor, Navarra: Thomson Reuters - Civitas, pp. 106-136.

$2 \quad$ Ver infra nota 12.
} 


\section{(1.1.1) Neutralidad y parcialidad / igualdad y desigualdad}

Tendencialmente al menos, el derecho común de los contratos se presenta como neutro frente a la posición de las partes en la negociación del contrato y el resultado que alcancen a través de estas. Lo que se procura es, en general, que el consentimiento se forme correctamente ${ }^{3}$. Si así sucede, la regla general es que el juez no disponga de espacio para interferir en el contenido del contrato acudiendo a consideraciones de justicia sustantiva ${ }^{4}$. Las limitaciones a la posibilidad de configurar el contenido de los acuerdos de las partes obedecen, más bien, a la protección de intereses sociales 5 .

Las cosas se plantean de forma diversa tratándose de la ley $\mathrm{n}^{\circ}$ 19.496. El legislador abandona la neutralidad, optando derechamente por favorecer la posición de la parte típicamente más débil: el consumidor ${ }^{6}$.

Mi sugerencia es que la neutralidad que suele caracterizar a las reglas de derecho común y la parcialidad que, generalmente, es propia de las reglas que disciplinan las relaciones de consumo, se explican porque una asunción propia del derecho de contratos (la igualdad entre las partes ${ }^{7}$ ) se invierte tratándose de la ley 19.496.

Resultará útil desarrollar esta última afirmación.

3 En este sentido, el compromiso del derecho común de contratos es, generalmente, con consideraciones de justicia procedimental. Ver De la maza Gazmuri, I. (2006). "Justicia contractual, contratos de adhesión electrónicos y buena fe”, en Corral Talciani, H., / Rodríguez Pinto, M.: Estudios de Derecho Civil, II Jornadas Nacionales de Derecho Civil, Olmué, Santiago: Editorial LexisNexis, pp. 571-592.

4 Dos ejemplos bien evidentes de esta afirmación se encuentran en el tratamiento de las cuestiones de justicia conmutativa respecto de la lesión enorme y de alteración sobrevenida de las circunstancias. En lo que se refiere a la lesión enorme, como resulta bien sabido, su aplicación se encuentra circunscrita a los supuestos identificados por el legislador. Las principales aplicaciones particulares de la lesión enorme en el derecho chileno tienen lugar a propósito del contrato de compraventa (artículos 1889 y siguientes CC), el contrato de permuta (art. 1900 CC), la aceptación de una asignación hereditaria (art. 1348), el mutuo (art. 2206) (A propósito de los mutuos de dinero debe considerarse, además, las operaciones de crédito de dinero reguladas en la ley 18.010, específicamente el artículo 8), la anticresis (art. 2443 CC) y la cláusula penal (art. 1544). Por lo que toca a la alteración sobrevenida de las circunstancias, como resulta bien sabido, el Código no contiene una regla general que autorice la modificación o resolución del contrato en estos casos. La posición de un importante sector doctrinario es que el juez no podría hacer ninguna de las dos cosas. Sobre el punto puede consultarse De la maza, Ińigo (2010). "Los efectos de la imprevisión", en prensa para Estudios de Derecho Civil VI.

5 Esa es la racionalidad que suele subyacer, por ejemplo, a las reglas sobre objeto ilícito y causa ilícita.

6 Una mirada, incluso desaprensiva, a la ley 19.496 permite acreditar esta afirmación. Así se explican, entre otras, figuras como el derecho de retracto, los deberes de información, y la prohibición de cláusulas abusivas

7 A este respecto resultan útiles las palabras de DíEz-Picazo, L. (2007). Fundamentos del Derecho Civil Patrimonial, Introducción. Teoría del contrato, 6a ed., Cizur Menor (Navarra): Thomson Civitas, p. 137, en mi opinión, perfectamente extrapolables al ámbito chileno, 
Una primera tarea que demanda esta caracterización de neutralidad del derecho común de los contratos y parcialidad de las reglas de protección al consumidor consiste en desentrañar qué es lo que se quiere significar con la expresión "igualdad".

La "igualdad" es, desde luego, un concepto plagado de significados ${ }^{8}$ y controversias ${ }^{9}$, sin embargo, puede afirmarse que, en el derecho de contratos, su significado suele restringirse a la idea según la cual el legislador considera que quienes negocian un contrato son capaces de tutelar adecuadamente sus propios intereses durante la negociación y ejecución del contrato.

La igualdad que se predica de las partes no es, desde luego, fáctica -evidentemente, no todas las personas que negocian contratos son capaces de proteger adecuadamente sus propios intereses- sino de de carácter normativo. La decisión del legislador es tratar a todas las personas, salvo casos extremos ${ }^{10}$, como si fueran capaces de protegerse a sí mismos, dejando que los contratos se ejecuten tal y como fueron convenidos.

En la ley 19.496 -en general, en las reglas de protección de los consumidores- la asunción es exactamente la inversa: la desigualdad de las partes, en términos de que una de ellas resulta incapaz de tutelar adecuadamente sus intereses en la negociación del contrato ${ }^{11}$. En otras palabras,

según las cuales uno de los presupuestos ideológicos sobre los que reposa nuestra comprensión del contrato es la igualdad entre las partes, en sus propios términos: "El segundo de los presupuestos ideológicos de la concepción moderna del contrato se encuentra en la idea de la sustancial igualdad de las partes contratantes. El contrato es el medio mejor de arreglo de los intereses privados porque es una obra común de dos contratantes, que se encuentran en igual situación y en un mismo plano económico. Es un arreglo entre las partes".

8 En este sentido, Pérez Luño, E. (2005). Dimensiones de la igualdad, Madrid: Dykinson, p. 16 , se ha referido a la "equivocidad significativa" del término.

$9 \quad$ En verdad, el problema es que la discusión acerca de la igualdad es inherente a cualquier teoría de la justicia y se encuentra envuelta, con mayor o menor intensidad prácticamente en cualquier controversia sobre filosofía política y en un número significativo de cuestiones de filosofía moral. Por ello, la cantidad de temas que roza (desde igualdad de oportunidades a igualdad entre hombres y animales) y la cantidad de preguntas que suscita (por ejemplo: ¿igualdad de qué? ¿igualdad entre quiénes? ¿en qué momento? ¿cómo se mide?) es inabarcable y lo mismo sucede con la bibliografía. Con todo, un atractivo intento por mostrar "el estado de la cuestión" actualmente puede encontrarse en Holtug, N. / Lippert-Rasmussen (edits.) (2007). Egalitarianism. New Essays on the Nature and Value of Equality, Oxford: Clarendon Press.

10 Así, por ejemplo, los incapaces.

$11 \mathrm{O}$, en otras palabras, su posición negociadora se encuentra desmedrada en términos de que no resultan capaces de participar significativamente en el contenido normativo del contrato. Ver, a este respecto, SLawson, D. (1996). Binding Promises: the Late 20th century reformation of contract law, New Jersey: Princeton University Press, p. 23. La idea de que las relaciones de consumo suelen caracterizarse por la desigualdad entre las partes constituye un lugar común en la literatura pertinente. Así, por ejemplo, Bercovitz Rodríguez-Cano, A. (1987). "La protección de los consumidores, la Constitución española y el derecho mercantil", en Bercovitz Rodríguez Cano, Alberto / Bercovitz Rodríguez Cano, Rodrigo: Estudios jurídicos sobre la protección de los consumidores, Madrid: Tecnos, p. 22, con toda elocuencia 
se asume la existencia de una desigualdad en la posición negociadora de las partes.

\section{(1.1.2) Asimetrías de información}

Actualmente suele considerarse que una de las causas más relevantes de la desigualdad entre proveedores y consumidores se encuentra en la presencia de asimetrías informativas entre estos y aquellos, en términos tales que dichas desigualdades se explicarían por las ventajas que, en términos de información, posee una de las partes -el proveedor- sobre la otra -el consumidor $-^{12}$.

La existencia de desigualdades entre proveedores y consumidores y la presencia de asimetrías informativas como una de las principales causas que explican dichas desigualdades pueden, a estas alturas, ser asumidas pacíficamente. Sin embargo, se puede avanzar alguna idea más, que no aparece suficientemente recogida por la doctrina nacional.

afirma: "La necesidad de que el consumidor sea protegido es consecuencia del reconocimiento de que existe una gran masa -la inmensa mayoría- de personas que al realizar las operaciones normales de la vida cotidiana, referidas principalmente a la adquisición de bienes y servicios, no están en condiciones de conseguir a solas unas calidades y unos precios adecuados. El prototipo del consumidor necesitado es la persona que individualmente no está en condiciones de hacer sus justas exigencias sobre los productos o servicios que adquiere y que carece de los medios necesarios para enfrentarse con las empresas con las que contrata". Respecto de la idea de desigualdad en la ley no 19.496 puede consultarse CorTez Matcovich, G. (2004). El nuevo procedimiento regulador en la ley no 19.496 sobre protección de los consumidores, Santiago: LexisNexis, pp. 1-4.

12 Ver, por ejemplo, Martínez de Aguirre y Aldaz, C., "Trascendencia del principio de protección a los consumidores en el derecho de obligaciones", $A D C, 47-1,1994$, p. 80; Pérez García, P. A. (1990). La información en la contratación privada. En torno al deber de informar en la Ley General para la defensa de los consumidores y usuarios, Madrid: Instituto Nacional de Consumo, pp. 69-73; Ortí Vallejo, A. (1992). "Comentario artículo 13", en Bercovitz, Rodríguez-Cano, R. / Salas Hernández, J.: Comentarios a la Ley General para la Defensa de los Consumidores y Usuarios, Madrid: Civitas, p. 404; Callejo Rodríguez, C. (2003). "El deber precontractual de información: del esquema tradicional del Código Civil al régimen del Derecho de Consumo", en Revista Jurídica del Notariado, No 47, p. 11; MoReno-Luque Casariego, C. (2007). "Protección previa a la contratación de bienes y servicios”, en León Arce, A. (dir.): Derechos de los consumidores y usuarios, 2a ed., Valencia: Tirant lo Blanch, Valencia, p. 196; Martínez de Aguirre, C., et al. (2008). Curso de Derecho Civil, vol. II, Derecho de obligaciones, 2a ed., Madrid: Colex, p. 408; Hadfield, G. / Howse, R. I Trebilcock, M. (1998). "Information-Based Principles for Rethinking Consumer Protection Policy", en Journal of Consumer Policy, vol. 28, p. 140; Howells, G. (2005). "The Potential and Limits of Consumer Empowerment by Information", en Journal of Law and Society, vol. 32, pp. 352-356; Vigneron-Maggio-Aprile S. (2006). Linformation des consommateurs en droit européen et en droit suisse de la consommation, Ginebra : Bruylant Schulthess, pp. 30-33 y Weatherill, S. (2005). EU Consumer Law and Policy, Cheltenham: Edward Elgar Publishing Limited, pp. 84-86. En el ámbito nacional puede consultarse a Tapia Rodríguez, M. I Valdivia Olivares, J.M. (2002). Contratos por adhesión. Ley No 19.496, Santiago: Editorial Jurídica de Chile, pp. 83-84; Cortez Matcovich (2004) 2 y Barrientos Zamorano, M. (2008). Daños y deberes en las tratativas preliminares de un contrato, Santiago: Legal Publishing, p. 97. 
La sugerencia es esta: las equivocaciones de los consumidores no solo se explican porque el proveedor no suministre la información necesaria, sino también por problemas de racionalidad imperfecta (imperfect rationality $)^{13}$.

En términos muy sencillos, el problema no consistiría, únicamente, en que el consumidor no disponga de acceso a la información que le permita una adecuada formación del consentimiento, sino que, aun disponiendo de dicho acceso, no necesariamente es capaz de utilizar la información adecuadamente. Un ejemplo de cada una de las causas del problema contribuirá a su mejor comprensión.

\section{(a) Falta de información}

Los supuestos de simple falta de información resultan intuitivamente más cercanos. Así, por ejemplo, la Segunda Sala de la Corte de Apelaciones de Santiago ${ }^{14}$ confirmó la sentencia que sanciona a una conocida multitienda al pago de una multa de 30 UTM por la no entrega de información veraz y oportuna a los consumidores en la venta de televisores plasma y LCD. En este caso, la información omitida se refería a la posible incompatibilidad de los aparatos con la eventual norma de emisión de televisión digital que se aprobara para Chile que, en definitiva, podía alterar la calidad de la imagen o alta resolución de los aparatos. La sentencia señala que el consumidor tiene derecho a conocer, antes de comprar, la información relevante sobre los productos, en este caso que el televisor LCD no se vería necesariamente como en la tienda, y que al no estar definida la norma digital en ese momento, probablemente se necesitaría decodificador si la norma no coincidía con las especificaciones técnicas del aparato.

El problema es, sencillamente, que no se suministró la información pertinente al consumidor.

13 Tomo esta idea de Bar-Gill, O. (2007). "Informing Consumers About Themselves", New York University Law and Economics Working Papers, p. 5. Disponible en http://lsr.nellco. org/cgi/viewcontent.cgi?article= 1115 \&context =nyu/lewp [Fecha de visita: 10 de julio de 2008]. Para comprender esta idea es necesario advertir que ha sido desarrollada como una crítica a la asunción de racionalidad de los sujetos que, generalmente, emplea el pensamiento económico. Véase, por ejemplo, Posner, R. (1998). "Rational Choice, Behavioral Economics, and the Law", en Stanford Law Review, vol. 50, pp. 1551-1575, según la cual (1) las personas poseen objetivos bien definidos y sus decisiones se encuentran orientadas hacia la maximización de dichos objetivos; (2) esas preferencias reflejan los costos y ventajas de las opciones disponibles para el sujeto; y, (3) en situaciones de incertidumbre las personas son capaces de utilizar la información disponible para evaluar sus probabilidades y son capaces de integrar nueva información disponible y reevaluar sus probabilidades.

14 Tomo la información del sitio web de SERNAC: http://www.sernac.cl/leyes/detalle. php?id=2448 [Fecha de visita: 26 de julio de 2010]. 


\section{(b) Racionalidad imperfecta}

La causa más compleja que explica la presencia de asimetrías informativas es la racionalidad imperfecta. A diferencia de la falta de suministro de información, en este supuesto el consumidor tiene acceso a ella, sin embargo no es capaz de hacer un uso adecuado de la misma.

Un ejemplo suficientemente conspicuo de esta segunda causa de asimetría informativa se encuentra en los contratos por adhesión ${ }^{15}$. En este

15 La idea de incapacidad del consumidor frente a contratos por adhesión posee una abultada bibliografía. Sobre ella puede consultarse De la Maza Gazmuri, I. (2003). "Contratos por adhesión y cláusulas abusivas: ¿Por qué el Estado y no solamente el mercado?” en Revista Chilena de Derecho Privado, No 1, pp. 109-147. En este trabajo (p. 128 nota 67) he intentado, siguiendo a Hillman, R. y Rachlinski, J. (2002). "Standard-Form Contracting in the Electronic Age”, en N.Y.U. L. Rev., vol. 77, pp. 429-456, una exposición sucinta de los factores que explican la incapacidad del consumidor sobre la que resulta útil volver aquí. Los consumidores se enfrentan a cuatro tipos de problemas en este ámbito. El primer problema tiene que ver con lo que se denomina racionalidad limitada (bounded rationality). En forma sumaria, la racionalidad limitada significa que los seres humanos disponen únicamente de capacidades computacionales limitadas y una memoria seriamente defectuosa. Un ejemplo de lo anterior, sugerido por Tversky y Kanheman, es que la gente tiende a concluir que los accidentes de automóviles son mucho más frecuentes de lo que en realidad son si es que han presenciado uno recientemente (citado en Jolls, C./ Sunstein, C. / Thaller, R. (2000). "A Behavioral Approach to Law and Economics", en Sunstein, C. (ed): Behavioral Law \& Economics, Nueva York: Cambridge University Press, pp. 14-15). Un análisis más detallado de las limitaciones a la racionalidad del modelo económico neoclásico en el caso de los consumidores puede encontrarse en Hanson, J. / Kysar, D. (1999). "Taking Behaviorism Seriously: Some evidence of Market Manipulation”, en Harv. L. Rev., vol. 112, passim.). Según dicho análisis, los consumidores rara vez acumulan toda la información necesaria. Esto incidiría, por ejemplo, en que no se detengan sobre la distribución de los riesgos remotos en un contrato por adhesión. El segundo problema es que las personas suelen tener dificultades para tomar aquellas decisiones que involucran la consideración de un número amplio de factores. Esto significa que, enfrentado a un contrato que involucra una pluralidad de factores, el consumidor tenderá a concentrarse únicamente en algunos de ellos, probablemente los más evidentes como el precio o el número de cuotas en que puede ser pagado dicho precio, dejando los demás de lado. El tercer problema es que, basados en estudios empíricos, algunos sicólogos sostienen que las personas suelen hacer inferencias consistentes con aquello que desean creer, interpretando información ambigua de manera que se acomode a sus creencias y deseos. Este fenómeno, una especie de disonancia cognitiva, puede implicar que los consumidores no consideren cierta información -respecto, por ejemplo a la distribución de riesgos realizada a través del contrato- pues esta tiende a desacreditar la decisión original del consumidor de comprar el producto. Finalmente, el cuarto problema es que existe alguna evidencia respecto a que los sujetos tienden a subestimar los riesgos que ellos mismos toman. En el problema que ocupa estas líneas, esto significa que los sujetos tienden a sobrestimar su capacidad de evaluar los riesgos incluidos en este tipo de acuerdos. En este sentido -y respecto a la responsabilidad por productos defectuosos- Calabresi, G. (1984). El costo de los accidentes, Barcelona: Editorial Ariel, p. 71, ha expuesto este argumento en la siguiente forma: "Aun cuando los individuos contaran con los datos necesarios para evaluar el riesgo [de un producto], serían incapaces, sicológicamente, de hacerlo. Se afirma que la gente no suele apreciar, racionalmente, la probabilidad de morir o la de sufrir un accidente grave. Estas cosas les ocurren a los demás -pensamos-; y no hay forma de que nos persuadan de que también pueden sucedernos a nosotros por muchas estadísticas que nos muestren". Sobre todo esto puede consultarse, además, para el caso específico de contratos 
tipo de negocios se suministra información a los consumidores respecto de las condiciones que configuran el contenido normativo del contrato, sin embargo, generalmente, los consumidores, por razones perfectamente comprensibles, no analizan dichas condiciones ${ }^{16}$.

\section{2) ¿Со́мо?}

Si la desigualdad entre consumidores y proveedores se explica -en una parte significativa al menos- a partir de las asimetrías informativas existentes entre ellos, entonces, fluye con toda naturalidad que la técnica de protección por la que se opte tenga por objeto corregir dichas asimetrías.

La pregunta acerca de qué técnica de corrección de las asimetrías debería emplearse depende de cuál sea la causa de dicha asimetría. Si ella es, simplemente, que una parte típicamente se encuentra en mejores condiciones que la otra de acceder a la información entonces la técnica consiste en la imposición del suministro de información. Si, en cambio, la causa obedece a problemas de racionalidad imperfecta, parece necesario acudir a otras técnicas como la privación de efecto a ciertas cláusulas en los contratos por adhesión o el derecho de desistimiento. En ese orden examino las técnicas de protección al consumidor.

\section{(1.2.1) El suministro de información}

Una mirada al derecho europeo del consumo muestra un intenso compromiso con la provisión de información como técnica de protección del consumidor, atendido el escaso desarrollo de la materia en la doctrina nacional, conviene comenzar dándole una sumaria mirada al derecho comunitario y luego detenerse sobre las ventajas y desventajas de esta técnica.

\section{(a) Una mirada al entorno comunitario}

En el ámbito comparado -notablemente en el entorno europeo- se ha considerado que una de las principales técnicas de protección de los consumidores consiste en el suministro de información, estableciéndose un "derecho a la información" respecto de los consumidores ${ }^{17}$.

por adhesión, Korobkin, R. (2003). "Bounded Rationality, Standard Form Contracts, and Unconscionability” en U. Chi. L. Rev., vol. 70, pp. 1203-1295.

16 Ver Tapia Rodríguez / Valdivia Olivares (2002) 62-66.

$17 \quad$ El Tratado de Ámsterdam de 2 de octubre de 1997 (Tratado de Ámsterdam por el que se modifican el Tratado de la Unión Europea, los Tratados constitutivos de las Comunidades Europeas y determinados actos conexos), establece, a través de su artículo 153, el derecho a 
Este derecho a la información se garantiza de diversas maneras. Algunas de ellas corren a cargo de la Administración Pública y se pueden concretar de maneras muy distintas, entre ellas, a través de la creación de oficinas de información al consumidor o estableciendo que los medios de comunicación de titularidad pública dediquen espacios y programas a la información y educación de los consumidores sobre su salud y seguridad en el consumo ${ }^{18}$.

Otra forma de garantizar el derecho a la información -la que interesa aquí- ya no depende de la Administración Pública, sino de los particulares. En esta segunda forma, el suministro de información corre a cargo de ciertos particulares a quienes, por el hecho de poner en circulación determinados bienes y servicios, se les impone el suministro de información. A nivel comunitario esta imposición se plasma a través de las Directivas comunitarias. La mayoría de ellas a propósito de relaciones de consumo ${ }^{19}$.

Tratándose del suministro de información existe una gran variedad reglas. Algunas de ellas no son propiamente precontractuales, sino que se imponen con independencia de si exista o no negociación de un contrato, así, por ejemplo, las reglas que disciplinan la publicidad de los productos

la información como uno de los mecanismos destinados a proveer de un alto grado de protección a los consumidores. El texto del artículo 153, que modifica el antiguo artículo 129 A del Tratado de Maastricht, dispone, en lo que aquí interesa: "Para promover los intereses de los consumidores y garantizarles un alto nivel de protección, la Comunidad contribuirá a proteger la salud, la seguridad y los intereses económicos de los consumidores, asi como a promover su derecho a la información, a la educación y a organizarse para salvaguardar sus intereses". Dicho precepto no fue modificado por el Tratado de Niza de 2001. Por su parte, el artículo 2 punto 20 del Tratado de Lisboa de 13 de diciembre de 2007 por el que se modifica el Tratado de la Unión Europea y el Tratado Constitutivo de la Comunidad Europea, mantiene este primer apartado del artículo 153, que ha quedado como el artículo 169 de la versión consolidada del Tratado de funcionamiento de la Unión Europea.

18 En la ley 19.496, su artículo 8 b) establece que una de las funciones de las organizaciones para la defensa de los derechos de los consumidores es "informar, orientar y educar a los consumidores para el adecuado ejercicio de sus derechos y brindarles asesoría cuando la requieran. Por su parte, el artículo 58 b) dispone que una de las funciones del SERNAC es: "Recopilar, elaborar, procesar, divulgar y publicar información para facilitar al consumidor un mejor conocimiento de las características de la comercialización de los bienes y servicios que se ofrecen en el mercado...".

19 Sobre esto puede consultarse Palacios González, M. (2003). "El deber de información en los contratos con consumidores", en Espiau Espiau, S. / Vaquer Aloy, A. (edits.): Bases de un derecho contractual europeo, Valencia: Tirant lo Blanch, pp. 89-96; Wilhelmsson, T. I Twigg-Flesner, CH. (2006). "Pre-contractual information duties in the acquis communautaire" en European Review of Contract Law, No 4, vol. 2, pp. 456- 457; y Vigneron-MaGGIO-APRILE (2006) 72-200. 
y servicios ${ }^{20}$, su precio ${ }^{21}$ o su etiquetado ${ }^{22}$. Respecto de las reglas orientadas directamente a mejorar la calidad del consentimiento contractual, se presta una especial atención a la forma en que se suministra la información pues se pretende que se realice en términos que permita su adecuada comprensión. Así, por ejemplo, en ocasiones se exige que la información

20 El artículo 2.2 de la Directiva 84/450/CEE del Consejo, de 10 septiembre de 1984, relativa a la aproximación de las disposiciones legales, reglamentarias y administrativas de los Estados Miembros en materia de publicidad engañosa, define publicidad engañosa como: "toda publicidad que, de una manera cualquiera, incluida su presentación, induce a error o puede inducir a error a las personas a las que se dirige o afecta y que, debido a su carácter engañoso, puede afectar su comportamiento económico o que, por estas razones, perjudica o es capaz de perjudicar a un competidor". Esta directiva fue luego modificada por la Directiva 97/55/CE del Parlamento Europeo y del Consejo de 6 de octubre de 1997 por la que se modifica la Directiva 84/450/CEE sobre publicidad engańosa, a fin de incluir en la misma la publicidad comparativa. La regulación de la publicidad en el entorno comunitario es completada por una serie de directivas sectoriales. Así, por ejemplo, la Directiva 89/552/CEE del Consejo de 3 de octubre de 1989 sobre la coordinación de determinadas disposiciones legales, reglamentarias y administrativas de los Estados miembros relativas al ejercicio de actividades de radiodifusión televisiva; la Directiva 90/314/CEE del Consejo, de 13 de junio de 1990, relativa a los viajes combinados, las vacaciones combinadas y los circuitos combinados; Directiva 2000/13/CE del Parlamento Europeo y del Consejo, de 20 de marzo de 2000, relativa a la aproximación de las legislaciones de los Estados miembros en materia de etiquetado, presentación y publicidad de los productos alimenticios; y Directiva 2001/83/CE del Parlamento Europeo y del Consejode 6 de noviembre de 2001 por la que se establece un código comunitario sobre medicamentos para uso humano. Un examen de estas Directivas en Vigneron-Maggio-Aprile (2006) 111-113.

21 El artículo 4 (1) de la Directiva 98/6/CE del Parlamento Europeo y del Consejo de 16 de febrero de 1998, relativa a la protección de los consumidores en materia de indicación de los precios de los productos ofrecidos a los consumidores, fija ciertos requisitos que debe cumplir la información sobre precios que se entregue al consumidor. Sobre los deberes de información que impone esta Directiva puede verse Schulte-Nölke, H. / MeyerSchwickerath, L. (2008). "Price Indication Directive (98/6)", en Schulte-Nölke, H., Twigg-Flesner, Ch. / Ebers, M. (edits.), EC Consumer Law Compendium. The Consumer Acquis and its transposition in the Member States, Munich: Sellier, pp. 374-375. El artículo 36 de la Directiva 2007/64/CE del Parlamento Europeo y del Consejo, de 13 de noviembre de 2007, sobre servicios de pago en el mercado interior, por la que se modifican las Directivas $97 / 7 / C E, 2002 / 65 / C E, 2005 / 60 / C E$ y 2006/48/CE y por la que se deroga la Directiva 97/5/CE, dispone, en lo pertinente que: "el proveedor de servicios de pago est [á] obligado a facilitar al usuario de servicios de pago, de un modo fácilmente accesible para él, la información y las condiciones establecidas en el artículo 37, antes de que el usuario quede vinculado por cualquier otro contrato u oferta relativos a una operación de pago de carácter único".

22 El artículo 6.1 de la Directiva 85/374/CEE de 25 de julio de 1985 relativa a la aproximación de las disposiciones legales, reglamentarias y administrativas de los Estados miembros en materia de responsabilidad por los dańos causados por productos defectuosos hace responsable al fabricante por sus productos defectuosos. Para determinar este carácter defectuoso se considera, entre otras cosas, la presentación del producto. En general, la doctrina ha estimado que dentro de los defectos a que alude la regla cabe comprender los de diseño, fabricación e instrucción. Ver Vigneron-Maggio-Aprile (2006) 91. Tratándose de defectos de instrucción lo que sucede es que, o bien no se suministró la información requerida, o esta se suministró incorrectamente. 
se entregue por escrito ${ }^{23}$, que la redacción sea de forma clara y comprensible $^{24}$, o inequívoca ${ }^{25}$.

\section{(b) Las ventajas y limitaciones de la imposición del suministro de in-} formación como técnica de protección a los consumidores

\section{(i) Ventajas}

La imposición del suministro de información a los proveedores suele preferirse a otras técnicas de protección por dos razones. La primera de ellas es que constituye la forma más suave de intervencionismo legal ${ }^{26}$. Comparada con otras formas de regulación -particularmente con la prohibición de ciertas prácticas-, resulta más compatible con una economía de libre mercado, en la que se espera que la intervención del Estado sea tan discreta como resulte posible. Por lo demás, al ser más compatible con los requisitos de una economía de libre mercado, resulta políticamente más factible su imposición ${ }^{27}$.

23 El artículo 4 de la Directiva 90/314/CEE de 13 de junio de 1990, relativa a los viajes combinados, las vacaciones combinadas y los circuitos combinados, establece para el comerciante el deber de informar al consumidor, generalmente, sobre el tratamiento de pasaportes y visados, e información relativa a formalidades sanitarias. Esta y otra información exigida debe entregarse por escrito o en cualquier otra forma comprensible y accesible al consumidor. Sobre los deberes de información que impone esta Directiva puede consultarse Schulte-Nölke, H. I Meyer-Schwickerath, L. (2008). "Package Travel Directive (90/314)" en Schulte-Nölke, H. / Twigg-Flesner, Ch. / Ebers, M. (edits.): EC Consumer Law Compendium. The Consumer Acquis and its transposition in the Member States, Munich: Sellier, pp. 133-158.

24 El artículo 5 de la Directiva 93/13/CEE del Consejo, de 5 de abril de 1993, sobre las cláusulas abusivas en los contratos celebrados con consumidores dispone que constando las cláusulas por escrito deberán estar redactadas siempre de forma clara y comprensible. Sobre el requisito de transparencia en la Directiva puede consultarse Ebers, M. (2008). "Unfair Contracts Term Directive (93/13)”, en Schulte-Nölke, H. / Twigg-Flesner, Ch. / Ebers, M. (edits.): EC Consumer Law Compendium. The Consumer Acquis and its transposition in the Member States, Munich: Sellier, pp. 245-250. Por su parte, los artículos 3 y 4 de la Directiva 2002/65/CE del Parlamento Europeo y del Consejo, de 23 de septiembre de 2002, relativa a la comercialización a distancia de servicios financieros destinados a los consumidores, establecen sendos deberes de información precontractual a cargo del proveedor. La información deberá, además, comunicarse de manera clara y comprensible y, en algunos casos, en soporte de papel u otro soporte duradero accesible.

25 El artículo 4 de la Directiva 97/7/CEE de 20 de mayo de 1997, relativa a la protección de los consumidores en materia de contratos a distancia, dispone un deber del comerciante de informar sobre ciertas características del bien o servicio y de la transacción. La información que se entregue al consumidor debe resultar inequívoca y facilitársele de modo claro y comprensible. Sobre los deberes de información que impone esta Directiva puede verse ScHulTE-Nölke, H. / Börger, A. (2008). "Distance Selling Directive (97/7)”, en Schulte-Nölke, H. / Twigg-Flesner, Ch. / Ebers, M. (edits.): EC Consumer Law Compendium. The Consumer Acquis and its transposition in the Member States, Munich: Sellier, pp. 327-340.

26 Ver Howells, G. (2005) 356; Zimmermann, R. (2000). Estudios de Derecho Privado Europeo, trad. A. Vaquer Aloy, Madrid: Civitas, p. 246, y Bar-Gill (2007) 63.

27 Ver BAR-GiLl (2007) 3. 
La segunda razón que aconseja preferir la imposición de deberes precontractuales de información en relaciones contractuales es que, a través de ellas se favorece el uso de la autonomía privada. Ciertamente puede sonar algo paradójico afirmar que imponer deberes a una parte durante la negociación de un contrato favorece la autonomía privada, porque, en principio, la imposición de cualquier deber constituye una intromisión no consentida que, por lo mismo, lesiona la libertad de las partes. Sin embargo, como parte de la doctrina alemana se ha encargado de advertir, el propósito de algunas limitaciones a la libertad de las partes es, precisamente, favorecer la libertad de contratación de los consumidores ${ }^{28}$. La imposición de deberes precontractuales de información al empresario no restringe la libertad de contratación del consumidor en la medida que no le impide participar en determinados negocios, y la favorece, en la medida que le facilita tomar decisiones en forma más libre. Haciéndolo, además, responsable por sus decisiones ${ }^{29}$.

\section{(ii) Limitaciones}

En conjunto con las ventajas que han quedado consignadas, la imposición del suministro de información a los proveedores como técnica de protección del consumidor reconoce ciertas limitaciones, algunas de carácter fáctico y otras de carácter normativo.

En lo que se refiere a las limitaciones de carácter fáctico, la primera de ellas queda determinada por los costos que supone una política de imposición de deberes precontractuales de información para la parte a quien se le imponen ${ }^{30}$. Desde luego el obstáculo no resulta relevante si se trata de información de la que el proveedor dispone, pero se torna más relevante si se le exige informarse para informar ${ }^{31}$.

28 Sobre esto ver Riesenhuber, K. (2001). "Party Autonomy and Information in the Sales Directive", en Grundmann, et al:: Party Autonomy and the Role of Information in the Internal Market, Berlín: De Gruyter, pp. 348-370.

29 Riesenhuber (2001) 368. En el mismo sentido Zimmermann (2000) 246, ha señalado que: "[l]a imposición de deberes de información (...) [n]o interfiere en el principio pacta sunt servanda, sino que trata de garantizar bases sólidas en la decisión de ambas partes de llegar a un acuerdo".

30 Ver BAR-Gill, n. 13, p. 63.

31 Así, por ejemplo, el artículo 5 de la Directiva 2001/95/CE del Parlamento Europeo y del Consejo de 3 de diciembre de 2001 relativa a la seguridad general de los productos, exige a los productores proporcionar a los consumidores información adecuada que les permita evaluar los riesgos inherentes a un producto. Asimismo, exige al productor mantenerse informado acerca de dichos riesgos. Es decir, el productor no solamente debe transmitir información que posee, sino que, además, debe invertir en mantenerse informado. Un buen ejemplo de deber de informarse para informar se encuentra, en el ámbito español, en los hechos que originaron la Sentencia del Tribunal Supremo de 2 de febrero de 2006 (RJ año 2006, p. 2694, ponente Excmo Sr. J.A. Seijas Quintana) contribuirán a ilustrar el punto. Se trata de una demanda contra una agencia de viajes que omitió informar a uno de sus 
Junto al problema de los costos -y probablemente bastante más relevante que estos- una segunda limitación queda configurada por problemas asociados a racionalidad imperfecta. Como ha sugerido Zimmermann respecto de la imposición de deberes precontractuales de información:

"En principio, la idea es excelente. Sin embargo, al mismo tiempo, se aprecian vagas reminiscencias de algunos de los ideales utópicos de la Ilustración. En primer lugar, muchas personas se resisten a cualquier tipo de instrucción forzosa: simplemente, no leen los larguísimos documentos que se les presentan. En segundo lugar, y mucho más importante, la cantidad de información obligatoria que se proyecta sobre el consumidor no siempre comporta un nivel de transparencia deseable: un consumidor al que se le proporciona una sobrecarga de información es tan incapaz de tomar una decisión informada como aquel que no recibe en absoluto ninguna. La imposición de deberes de información al empresario, en otras palabras, no siempre es un remedio que pueda mitigar el déficit de información del consumidor" 32 .

De esta manera, factores como las capacidades computacionales limitadas de los seres humanos, sus prejuicios, la subestimación de los riesgos o la sobreestimación de sus capacidades ${ }^{33}$, determina que las personas no siempre puedan utilizar adecuadamente la información que se les suministra en la negociación de un contrato

En lo que toca a las limitaciones normativas, estas se derivan del diseño del ordenamiento jurídico, específicamente de ciertos principios sobre los que reposa el derecho de contratos.

Para comprender estas limitaciones, es necesario advertir, en primer lugar, que suele aceptarse que en ciertas relaciones caracterizadas por la desigualdad de las partes en los términos de aquellas consideradas en este capítulo, el principio de que cada parte debe protegerse a sí misma -y, por lo tanto, procurarse su propia información- se invierte. Esto significa que se asume que una parte debe tutelar los intereses de la otra suminis-

clientes que había contratado un viaje a Egipto, de los comunicados públicos de una organización terrorista a propósito de los cuales la Secretaría General de Turismo había remitido a la Federación Española de Agencias de Viaje y a la Asociación Empresarial de Agencias de Viaje una carta en la que recomendaba que los turistas se abstuvieran de desplazamientos por superficie (barco, tren o automóvil) desde el límite sur de El Cairo hasta Luxor. La agencia de viajes no informó de ello al demandante y mientras este viajaba en autobús por la zona indicada, el vehículo fue ametrallado por una banda de terroristas. Como consecuencia del atentado, el hijo del demandante murió y él y su mujer resultaron heridos. En lo que es relevante aquí, el TS sostuvo que a la agencia de viajes "le incumbía un específico deber profesional de conocer cuál era la situación del país de destino y cuál el riesgo que implicaba para su cliente, pues solo así podía informar a este, incumpliendo ese deber de informarse e informar a su cliente" (Sentencia del Tribunal Supremo de 2 de febrero de 2006, FD 9).

32 Zimmermann (2000) 246-247.

33 Ver supra nota 15. 
trándole información ${ }^{34}$. Sin embargo, existe un límite para esta tutela. Como acertadamente han advertido Malaurie, Aynès y Stoffel-Munck la vocación del derecho no ha sido jamás, ni debe llegar a ser, convertir a los agentes jurídicos en incapaces ${ }^{35}$. Por lo mismo si, en los hechos, la parte más débil puede fácilmente conseguir la información, no se ve por qué debería asignársele el deber de proporcionársela a la otra parte ${ }^{36}$.

\section{(1.2.2) Otras técnicas de protección a los consumidores}

Las limitaciones recién apuntadas, de carácter fáctico y normativo, permiten comprender la convivencia de la imposición del suministro de información con, de una parte, técnicas diversas de protección como la

$34 \quad$ Ver supra nota 12.

35 Malaurie, Ph. / Aynès, L. / Stoffel-Munck, Ph. (2003). Les obligations, 3a ed., París: Defrénois, p. 191.

36 Esta idea no es, en absoluto, ajena a las normas de protección de los consumidores, en las que suele considerarse que un comportamiento negligente de estos redunda en su perjuicio. Así, por ejemplo, el artículo 2.3 de la Directiva 99/44/CE, que regula la conformidad del bien mueble en el contrato de compraventa, dispone: "Se considerará que no existe falta de conformidad a efectos del presente articulo si en el momento de la celebración del contrato el consumidor tenía conocimiento de este defecto o no podía fundadamente ignorarlo, o si la falta de conformidad tiene su origen en materiales suministrados por el consumidor". En un sentido similar, el artículo 5.1 de la Directiva 2001/95/CE relativa a seguridad de los productos: "Dentro de los limites de sus respectivas actividades, los productores proporcionarán a los consumidores información adecuada que les permita evaluar los riesgos inherentes a un producto durante su periodo de utilización normal o razonablemente previsible, cuando estos no sean inmediatamente perceptibles sin avisos adecuados, a fin de que puedan precaverse de dichos riesgos". Lo que se desprende del artículo 2.3 de la Directiva 99/44/CE es que si el consumidor conocía o debía conocer el defecto, no puede, después, alegar falta de conformidad. Por su parte, el artículo 5.1 de la Directiva 2004/95/CE impone el deber de proporcionar a los consumidores información sobre los riesgos de un producto, salvo que estos sean perceptibles. En ambos preceptos se impone al consumidor un cierto nivel de diligencia para gozar de la protección que le brindan las respectivas Directivas. Lo que subyace a las Directivas es una idea central en el derecho de contratos que no debe olvidarse -aunque sí matizarse (Véase Barros Bourie, E. (2006). Tratado de responsabilidad extacontractual, Santiago: Editorial Jurídica de Chile, pp. 1024-1025) - en las relaciones de consumo y otras similares: los contratantes no deben ser tratados como incapaces, liberándolos de responsabilidad por sus decisiones, esto es lo que suele denominarse el "principio de la autorresponsabilidad". Con respecto a este principio, como resulta bien sabido, se puede ser responsable en, al menos, dos sentidos distintos: Cariota Ferrara, L., El negocio jurídico, trad. M. Albaladejo, Aguilar, Madrid, 1959,, p. 53. Ver, también, Pietrobon, V. (1971). El error en la doctrina del negocio jurídico, trad. M. Alonso Pérez, Madrid: Editorial Revista de Derecho Privado, pp. 268-269), relacionando, en sede de error, la autorreponsabilidad con la protección de la confianza de la parte que recibe la declaración. De una parte, frente a terceros, en cuyo caso, la responsabilidad se traduce en una obligación de indemnizar los perjuicios causados. De otra parte, se puede ser responsable en el sentido de que las declaraciones de voluntad que formula una persona le son imputables. A este segundo sentido puede denominársele "autorresponsabilidad" y, en sede de negociaciones de un contrato, significa que, bajo ciertas condiciones, la persona que celebra un contrato debe "sufrir los efectos del negocio que realiza", aún cuando no los desee. Así sucede, por ejemplo, con el error inexcusable, el dolo bueno y la reserva mental. 
invalidez de ciertas cláusulas y el desistimiento unilateral y, de otra parte, con la carga de autoinformarse del consumidor.

\section{(a) Invalidez}

En lo que respecta a la invalidez, el artículo 16 de la ley 19.496, entre sus letras a) y f) contiene una "lista negra" 37 de cláusulas cuya incorporación a un contrato produce como consecuencia la nulidad de las mismas. El sistema de control a este respecto no descansa sobre la provisión de información acerca de las cláusulas ${ }^{38}$, sino que se recurre a una métrica externa a la negociación del contrato, a una cierta tipificación de las exigencias de la justicia conmutativa en las relaciones de consumo ${ }^{39}$.

\section{(b) Desistimiento}

Por lo que toca al desistimiento, la ley no 19.496, particularmente después de la reforma que introdujo la ley $\mathrm{n}^{\circ} 19.555$, establece una serie de supuestos en los cuales se permite al consumidor el derecho a separarse discrecionalmente de un contrato ya perfeccionado ${ }^{40}$. Como sucede con las cláusulas abusivas de la lista negra, la justificación en los supuestos en que se autoriza el desistimiento no se relaciona necesariamente con la falta de información -la cláusula puede privarse de eficacia aun cuando el consumidor la haya conocido-, el consumidor puede desvincularse del contrato aun cuando se le haya suministrado toda la información pertinente, sino con problemas de racionalidad imperfecta del consumidor, este no resulta capaz de evaluar adecuadamente la cláusula o el bien o servicio que está adquiriendo ${ }^{41}$.

37 Sobre la idea de "lista negra" consultar De la maza Gazmuri, I. (2004). "El control de las cláusulas abusivas y la letra g)" en Revista Chilena de Derecho Privado, Fernando Fueyo Laneri, No 3, pp. 35-68.

38 No obstante existen reglas de inclusión en el artículo 17 de la ley 19.496. Sobre la insuficiencia de la información como remedio de las cláusulas abusivas ver De LA MAZA GAZMURI, I. (2003). "Contratos por adhesión y cláusulas abusivas: ¿Por qué el Estado y no solamente el mercado?" en Revista Chilena de Derecho Privado, No 1, pp. 109-147.

39 El análisis de estas cláusulas puede consultarse en Tapia Rodríguez / Valdivia Olivares (2002), pp. 80-89.

40 Sobre el derecho de desistimiento en materia de consumidores puede consultarse Beluche Rincón, I. (2009). El derecho de desistimiento del consumidor, Valencia: Tirant lo Blanch. En el ámbito nacional, una breve descripción de los supuestos de desistimiento unilateral en la ley no 19.496 en Pizarro Wilson, C. (2005). "El incumplimiento lícito del contrato por el consumidor: "El derecho de retracto" en Actualidad Jurídica, Año VI, No. 11. En la ley 19.496 pueden consultarse los artículos 3 bis y 3 ter.

41 Respecto de la insuficiencia del suministro de información como técnica de protección frente a los casos en que se autoriza desistimiento del consumidor Peguera Poch, M. (2008). "En el menú 'opciones', elija 'deshacer': el derecho a desistir del contrato electrónico", en Cotino Hueso, L. (Coord.): Consumidores y usuarios ante las nuevas tecnologías, Valencia, 


\section{(iii) Cargas}

En lo que se refiere a la carga de autoinformarse. La doctrina nacional ha entendido por carga "la necesidad de adoptar una cierta conducta si se quiere lograr un cierto resultado" 42 . La ley 19.496 se refiere a la carga de autoinformarse -aunque con una cierta imprecisión técnica- en su artículo 3. El precepto dispone que [Son derechos y deberes básicos del consumidor]:

b) El derecho a una información veraz y oportuna sobre los bienes y servicios ofrecidos, su precio, condiciones de contratación y otras caracteristicas relevantes de los mismos, y el deber de informarse responsablemente de ellos;

Más adelante habrá oportunidad de examinar el precepto con mayor detención, por ahora importa ocuparse sobre "el deber de informarse responsablemente" y preguntarse en qué sentido se trata de un "deber". Y la respuesta es que no se trata de un deber. Para advertirlo basta constatar que un requisito esencial para que lo fuera es que su infracción determinara algún tipo de responsabilidad; en este caso eso no sucede $e^{43}$.

En realidad, la norma opera de otra forma, quien tiene un deber de informar es el proveedor, si lo incumple debe indemnizar los daños que produzca al consumidor. Por su parte, este último debe informarse razonablemente, de otra manera no logrará el resultado, es decir la indemnización de dańos y perjuicios que le haya ocasionado la falta de información $^{44}$.

Tirant lo Banch, pp. 95-96, comenta: "el derecho de desistimiento en el caso de los servicios constituye un margen para que el consumidor pueda reflexionar sobre la oportunidad de haber contratado ese servicio, de haber decidido ese gasto. Se está proporcionando un remedio al déficit de reflexión, a la precipitación en la celebración del contrato". Una penetrante mirada a la justificación sicológica de la falta de reflexión en Camerer, C. / Issacharoff, S. I Lowenstein, G. / Rubin. M. (2003). "Regulation for Conservatives: Behavioral Economics and the Case for "Asymetric Paternalism" en U. Pa. L. Rev., vol. 151, p. 1241.

42 Peñailillo Arévalo, D. (2003). Obligaciones. Teoría general y clasificaciones. La resolución por incumplimiento, Santiago: Editorial Jurídica de Chile, p. 80. Sobre esto puede consultarse, además, Díez-Picazo, L. (2008). Fundamentos de derecho civil patrimonial, vol. II, Las relaciones obligatorias, 6a ed., Cizur Menor (Navarra): Thomson Civitas, pp. 134-138.

43 Esta misma crítica es formulada por Treitel (1999). The Law of Contract, 11 a ed., Londres: Sweet \& Maxwell, p. 910 a propósito del "deber" de mitigar el daño. Por su parte, Barros Bourie (2006), señala que: "A diferencia del deber, la carga no impone a la víctima una conducta, sino establece un requisito, relativo a su propia conducta, como condición para que tenga derecho a ser indemnizada por todos sus daños".

44 Un problema distinto es la entidad de la carga del consumidor. Es dable aceptar que, por las posiciones que ocupan las partes en la negociación dicha carga, las más de las veces será extremadamente leve. En este sentido, resulta interesante la sentencia de la Audiencia Provincial de La Coruña de 11 de marzo de 2005 (AC 2005, 2259) sobre un contrato de préstamo 
En la primera parte de este trabajo me ha interesado mostrar -aunque sinópticamente- la relación que existe entre las razones que justifican la protección de los consumidores y las técnicas que se emplea para hacerlo. Si se asume (1) que la razón es la desigualdad de las partes y que esta se explica generalmente en términos de asimetrías informativas y (2) que, por su parte, estas últimas obedecen a simple falta de información o a problemas de racionalidad imperfecta, puede aceptarse que, como sucede en el derecho comparado y nacional: (a) una técnica de protección del consumidor es la imposición de deberes precontractuales de información a los proveedores y (b) que dicha técnica debe convivir con otras en aquellos supuestos en los cuales el problema no es la falta de información, sino la incapacidad de efectuar una decisión razonable a la luz de los propios intereses.

\section{2) EL SUMINISTRO DE INFORMACIÓN EN LA LEY 19.496}

En la segunda parte de este trabajo me interesa ocuparme del suministro de información en la ley 19.496. Comienzo advirtiendo los diversos intereses que subyacen a las reglas que imponen el suministro de información. A continuación me detengo sobre la norma general respecto de deberes precontractuales de información en dicha ley.

\section{1) LA INFORMACIÓN Y LOS INTERESES}

Una mirada atenta al contenido de la ley 19.496 muestra que las reglas contenidas en ella que imponen el suministro de información lo hacen en procura de la protección de intereses diversos.

al consumo en la que se señala que: “(...) no puede extenderse la protección al consumidor hasta el punto de considerarlo un incapaz. Ciertamente en los últimos años, y mayoritariamente por imposición de Directivas comunitarias, se ha desarrollado en España una legislación muy proteccionista de los consumidores y usuarios. Pero esta normativa tuitiva no puede llevarse a extremos tales que supongan, en la práctica, privar de derechos civiles a los ciudadanos, convirtiéndolos en auténticos incapaces, hasta el punto de que el otorgamiento de un contrato carezca de todo valor jurídico simplemente porque el consumidor afirme "que no lo leyó", o que no sabía lo que hacía. Esto puede llevar a la defenestración de las relaciones negociales. Son personas mayores de edad, con plenos derechos civiles, y por lo tanto responsables de sus contrataciones. Las normas indicadas tienen la finalidad de exigir mayores garantías a los empresarios y proveedores, no dejarlos inermes ante suministros defectuosos, o que no se abuse de la posición dominante del proveedor. Pero nunca exonerarlos de lo que pueden ser malos negocios o errores en la toma de decisiones personales". 


\section{(2.1.1) La libertad contractual}

Desde luego, el más evidente es lo que podría denominarse la "libertad contractual" de los consumidores, entendida como la libertad de decisión ${ }^{45}$, es decir que las personas solo quedan vinculadas por un contrato cuando así lo deciden y que esa decisión no solo debe ser libre en el sentido que no sea coaccionada, sino, además de que sea querida y esto último precisa que la decisión se haya tomado con la información suficiente ${ }^{46}$. En este sentido los deberes precontractuales de información suelen considerarse como medidas que tutelan la correcta formación de la voluntad, favoreciendo un consentimiento libre y reflexivo ${ }^{47}$. Así, aparece, en forma suficientemente evidente, por ejemplo, en el artículo 32 respecto de las condiciones en que se entiende formado el consentimiento tratándose contratos celebrados por medios electrónicos, y en aquellos en que se aceptare una oferta realizada a través de catálogos, avisos o cualquiera otra forma de comunicación a distancia.

\section{(2.1.2) La libre competencia}

Sin embargo, la libertad contractual no es el único interés. Si se presta atención a los artículos 28 y siguientes de la ley 19.496 se advierte que también se disciplina el suministro de información a través de la publicidad. Ahora bien, si se considera esta disciplina aparece que una de las principales cuestiones que preocupan al legislador es que la publicidad no sea engańosa, es decir que no induzca a error o engaño. Sin embargo, de ahí no se sigue -sería absurdo pretenderlo- que la publicidad se encuentre destinada a suministrar información que permita que el consumidor tome

45 Sobre la relación entre deberes precontractuales de información y la libertad de decisión ver Ehmann, H. / Sutschet, H. (2006). La reforma del BGB. Modernización del derecho alemán de obligaciones, trads. C. López Díaz y U. Salas de Sánchez, Bogotá: Universidad Externado de Colombia, pp. 204-205.

46 Desde luego, este no es el único sentido en que se puede utilizar la expresión "libertad contractual", junto a él existen, al menos, otros tres: (a) libertad entendida como no interferencia del Estado (es decir libertad negativa); (b) libertad en el sentido de disponer de opciones genuinas y valiosas (libertad positiva) y; libertad en el sentido de disponer de cierta protección del Estado respecto de ciertas actividades. Ver Eidenmüller, H. / Faust, F. / Grigoleit, H. / Jansen, N. / Wagner, G. / Zimmermann, R. (2008). "The Common Frame of Reference for European Private Law Policy Choices and Codification Problems" en Oxford Journal of Legal Studies, vol. 28-4, pp. 670-671. En esta investigación, sin embargo, utilizaré únicamente, el primer sentido.

47 Ver, por ejemplo, Terré F. / Simler, Ph. / Lequette, Y. (1996). Droit civil. Les obligations, 6a ed., París: Dalloz, p. 165. Ver también Grisi, G. (1989). Voz: "Informazione (obblighi di)", en AA.VV: Enciclopedia Giuridica, vol. XVI, Roma: Istituto della Enciclopedia Italiana, p. 13. Como ha sugerido Larroumet, Ch. (2007). Droit civil, t. III, $1^{\text {a }}$ parte, Les obligations. Le contrat, $6^{a}$ ed., París: Economica, p. 313, "[el deber de informar] constitue une excellente prévention contre l'erreur ou le dol". 
su decisión de la manera más informada posible. La regulación de la publicidad no protege -no predominantemente al menos- la libertad contractual ${ }^{48}$, sino más bien una de las condiciones de la libre competencia: la transparencia del mercado ${ }^{49}$.

\section{(2.1.3) El interés de conservación}

Un tercer interés cuya protección promueven algunas de las reglas que disciplinan el suministro de información es lo que podría denominarse un "interés de conservación". Existen ciertos supuestos en los cuales la finalidad con la que se impone el suministro de información no es, prioritariamente, la protección de la libertad contractual, sino la protección de la persona que adquiere el bien o servicio y de sus bienes. Ese parece ser el caso de las disposiciones de la ley 19.496 que regulan el suministro de información respecto de la seguridad de los productos y servicios. La información que debe suministrarse no se encuentra orientada a la formación del consentimiento del consumidor (por ejemplo, en la mayoría de los casos, saber que un aerosol es inflamable o que un determinado líquido es tóxico no determinará la decisión de adquirirlo o no) sino a la seguridad de su consumo, es decir a evitar daños en la persona o propiedad de quien lo utiliza ${ }^{50}$.

48 Las reglas sobre publicidad no imponen deberes de informar sino que, por así decirlo, sancionan la desinformación.

49 Ver Pascuau Liaño, M. (1992). "Comentario artículo 8", en Bercovitz Rodríguez-Cano, R. y Salas Hernández, J.: Comentarios a la Ley general para la defensa de los consumidores y usuarios, Madrid: Civitas, p. 143 señalando: "La publicidad es (...) una manifestación o componente de la libertad de empresa, y no cabe reducirla a un instrumento de política de educación e información de los consumidores. Si es tal, la publicidad busca la incitación o la persuasión, y no la información”. Sobre el suministro de información y la protección de la competencia en el mercado, un breve comentario en García Vicente, JR. (2009). "Comentario Artículo 60", en Bercovitz Rodríguez-Cano, R. (coord.): Comentario del Texto Refundido de la Ley General para la Defensa de los Consumidores y Usuarios y otras leyes complementarias, Cizur Menor (Navarra): Aranzadi Thomson Reuters, p. 770. En una sentencia de 15 de abril de 2008, la Corte de Apelaciones de Santiago (Servicio Nacional del Consumidor SERNAC con Farmacias Cruz Verde S.A., No Legal Publishing 38824) conociendo de un caso sobre una promoción efectuada por una cadena de farmacias señala, respecto del artículo 35 de la ley: "Que lo perseguido por el legislador con las normas invocadas por el denunciante es mantener y resguardar la debida transparencia y claridad de los programas de promoción lanzados por el comercio".

50 Un par de ejemplos servirán para mostrar la preeminencia de la protección del interés de conservación. El primero de ellos se encuentra en la STS de 29 de mayo de 1993 (RJ 1993,4052, pte. Excmo. Sr. D. P. González Poveda. Con comentario de Bercovitz RodríGuez-Cano, R. "Sentencia del Tribunal Supremo de 29 de mayo de 1993", en CCJC, 32, 1993, pp. 673) y se refiere a un caso en el que una persona utilizó benceno nitración como detergente en las proximidades de un fuego, resultando dañada. El etiquetado del producto no contenía la mención "no apto para el uso doméstico" y, por lo mismo el TS consideró que no se informaba suficientemente acerca de este riesgo. En el segundo ejemplo se trata de la explosión de una bombona de gas butano frente a la cual, la Audiencia de Bilbao consi- 


\section{2) LA REGLA GENERAL}

La determinación de los intereses del apartado anterior no constituye una summa divisio, sino una cuestión de énfasis, la utilidad que presta para efectos de este trabajo es simplemente permitirme circunscribir el supuesto de suministro de información que examinaré en las páginas restantes.

Se trata de uno en el cual el énfasis se encuentra en la protección de la libertad contractual. Prescindo, entonces, de la regulación de la publi$\operatorname{cidad}^{51} \mathrm{y}$, en general, de los instructivos cuando se trata de riesgos del producto o servicio. Limitaré, entonces, el uso de la expresión "deberes precontractuales de información" a aquellos supuestos en los que predominantemente se procura tutelar la libertad contractual.

Respecto de estos supuestos, es posible distinguir entre una regla general, la del artículo 3 b) y supuestos específicos ${ }^{52}$. Mi análisis se limita a la primera ${ }^{53}$, cuyo tenor, conviene recordarlo, es el siguiente:

deró que ni el productor ni el distribuidor de las bombonas habían logrado acreditar que en el producto existiera información que alertara en términos patentes y claros sobre los riesgos de la manipulación del producto que entrañen un uso incorrecto del mismo (ver REYEs López, M.a / Puertes Martí, A. / Estruch Estruch, J. / Montés Rodríguez, P. (1995). Jurisprudencia en materia de protección de consumidores y usuarios, Valencia: Editorial Práctica de Derecho, pp. 559-561). En ambos ejemplos, la información que se dejó de suministrar no se refiere, exactamente, a la satisfacción del interés contractual, es probable que la voluntad de adquirir un determinado líquido inflamable (por ejemplo, con fines de limpieza o desinfección) o una bombona de gas butano, no se vea afectada por el conocimiento del consumidor respecto de que el líquido no se deba aproximar la fuego o la bombona no se pueda manipular de ciertas maneras (por ejemplo mediante presiones e incisiones en la válvula). Lo que está en juego -la finalidad de la información- es la protección de la persona y bienes del adquirente del bien o servicio. Este interés es el que suelen proteger las reglas que exigen suministrar información sobre los riesgos del uso o consumo de bienes y servicios. Así, por ejemplo, se ha sugerido que las normas de protección del consumidor que exigen suministrar información sobre bienes y servicios de cuyo uso o consumo se pueda derivar un riesgo para el consumidor o usuario constituyen: "una medida preventiva de la integridad de la salud y seguridad de los consumidores y usuarios". Navarro Munuera, A. (1992). "Comentario artículo 3", en Bercovitz Rodríguez-Cano, R. y Salas Hernández, J.: Comentarios a la Ley general para la defensa de los consumidores y usuarios, Madrid: Civitas, p. 90.

51 Sobre las diferencias entre deberes precontractuales de información y publicidad puede consultarse Ortí VALLEJo (1992) 409-410.

52 Los más importantes, en mi opinión son los relativos a contratos celebrados por medios electrónicos que regulan los artículos 12 A y 32 y los relativos a crédito al consumo del artículo 37. Junto a ellos podrían, todavía, considerarse los artículos 14 y 30.

53 A la regulación de los contratos electrónicos me he referido en otras ocasiones. Ver De LA MAZA GAZMURI, I. (2009). "Ofertas sujetas a reserva: a propósito de los términos y condiciones en los contratos celebrados por medios electrónicos", en Revista de Derecho Universidad Austral de Chile, vol. 22 No 2, pp. 75-95 y De la Maza Gazmuri, I. (2005). "Los contratos por adhesión en plataformas electrónicas: una mirada al caso chileno" en SCRIPT-ed, vol. 2, no 3, disponible en http://www.law.ed.ac.uk/ahrb/script-ed/vol2-3/contratos.asp [Fecha de visita: 25 de julio de 2010]. Respecto del crédito al consumidor, el artículo 37, en lo que aquí interesa, se limita más bien a establecer un catálogo de información que el proveedor debe suministrar al proveedor, por lo mismo, si se examina el régimen general de los debe- 
[Son derechos y deberes básicos del consumidor:] b) El derecho a una información veraz y oportuna sobre los bienes y servicios ofrecidos, su precio, condiciones de contratación y otras características relevantes de los mismos, y el deber de informarse responsablemente de ellos;

Para analizar el precepto me haré cargo de tres tareas distintas. La primera de ellas consiste en determinar en qué sentido puede afirmarse que se trata de la regla general en lo que refiere a deberes precontractuales de información en la ley 19.496. A continuación me detengo sobre la fisonomía de la regla, y concluyo con las consecuencias de su incumplimiento.

\section{(a) La generalidad de la regla}

La generalidad del artículo 3 b) puede predicarse en dos sentidos.

En primer lugar, su tenor indica que, a diferencia de lo que sucede en el derecho común de los contratos -en el cual suele considerarse que el deber de suministrar información durante la negociación del contrato es excepcional-, tratándose de contratos encuadrados en relaciones de consumo, existe un deber general del proveedor de suministrar información al consumidor en la etapa previa a la formación del consentimiento ${ }^{54}$.

De aquí puede desprenderse una conclusión extremadamente relevante. Tratándose del derecho común de los contratos parece aceptarse

res de información en la ley 19.496 su interés, para un trabajo como este resulta más bien residual. Lo cual, desde luego, no significa que el crédito al consumo no sea un fenómeno jurídicamente desafiante. Sobre el tema puede consultarse Aguilar Ruiz, L. (2001). La protección legal del consumidor de crédito, Valencia: Tirant lo Blanch. Finalmente, en lo que se refiere al artículo 14, es decir información sobre las deficiencias del producto, el hecho de que sea usado o refaccionado o en cuya fabricación se hayan utilizado partes o piezas usadas, la verdad es que resultaría más sensato introducir dicho deber en la norma general, lo mismo, por supuesto, puede decirse sobre la información relativa al precio según el artículo 30. Me detengo sobre esto más adelante, ver infra notas 61 y 62 .

54 Ver, por ejemplo, Gómez Segade, J. (1980). "Notas sobre el derecho de información del consumidor” en RJC, No 3, p. 701 y Martínez de Aguirre y Aldaz (1994), pp. 79-80. Conviene citar con alguna latitud las palabras de este último autor (citas internas omitidas): "De acuerdo a la teoría tradicional, corresponde a cada uno de los contratantes adquirir la información precisa sobre las prestaciones objeto del contrato y el alcance tanto de su compromiso como el de su contraparte (caveat emptor, emptor debet esse curiosus). Los eventuales problemas se resuelven -fundamentalmente- bien por la vía de los vicios del consentimiento que pone el acento en los aspectos psicológicos del consentimiento, bien por la de los vicios ocultos (para un supuesto concreto). Este principio y estos mecanismos jurídicos se revelan insuficientes cuando existe, como ocurre actualmente en relación con los consumidores, una situación de déficit de información a cargo del consumidor, que puede afectar notablemente a la calidad de su consentimiento contractual; déficit cuya superación tiene costes excesivos para el consumidor, pero que podría ser fácilmente suplido mediante la información facilitada por el profesional (...) De ahí que se haya invertido la regla tradicional, imponiendo a los profesionales un genérico deber de información respecto al consumidor que supla el déficit informativo (...) y garantice así que se trata de un consentimiento suficientemente ilustrado, apto para fundamentar una decisión razonable”. 
que la regla general es que cada uno de los contratantes debe procurarse su propia información, por lo mismo, en principio debe asumirse que cada parte soporta el costo de su ignorancia, salvo que exista una buena razón para establecer un deber precontractual de informar. Tratándose de las relaciones de consumo se ha establecido un amplísimo deber precontractual de informar para el proveedor, por lo mismo, en general -salvo que exista una buena razón- debe asumirse que el riesgo del error del consumidor es soportado por el proveedor.

En segundo lugar, es posible afirmar que se trata de una regla general en la medida que no se encuentra circunscrita a tipos contractuales específicos o a bienes o servicios determinados, su alcance se extiende a toda relación de consumo.

En este sentido, por ejemplo, son específicos los deberes precontractuales de información del artículo 32 en la medida en que se limitan a contratos celebrados por medios electrónicos, y a aquellos en que se aceptare una oferta realizada a través de catálogos, avisos o cualquier otra forma de comunicación a distancia. Igualmente sucede con el supuesto del artículo 37 que se limita a los actos de consumo en que se conceda crédito directo al consumidor.

\section{(b) La fisonomía de la regla}

Dar cuenta de la fisonomía de la regla general del artículo 3 b) supone prestar atención, al menos, a los siguientes extremos: i) las cualidades que se exigen a la información, ii) su contenido, y iii) las consecuencias del incumplimiento del deber precontractual de informar.

\section{(i) Las cualidades de la información} Dispone el artículo 3 b) que la información debe ser "veraz y
oportuna".

Un primer comentario respecto a estos requisitos se refiere a la finalidad de la información.

Parece evidente que dicha finalidad consiste en que la voluntad que se presta en el contrato sea libre y espontánea, es decir, que se forme de una manera consciente, racional y libre ${ }^{55}$. De manera que la pregunta que

55 Ver Weatherhill, S. (2001). "Justifying Limits to Party Autonomy in the Internal Market", en Grundmann, et al.: Party Autonomy and the Role of Information in the Internal Market, Berlín: De Gruyter, p. 180, señalando que las normas que imponen deberes de información tienen como propósito mejorar la autonomía privada (party autonomy) del consumidor permitiéndole participar de una forma más informada en la negociación. El mismo autor justifica este tipo de medidas desde una perspectiva eficientista señalando: “ $t \mathrm{t}]$ he assumption is that without such intervention the market fails because of informational deficiencies on the part of consumer which generate inefficient choices". En el mismo sen- 
conviene formularse es si las cualidades que exige el precepto a la información que debe suministrar el proveedor resultan suficientes con vistas a este objetivo.

La respuesta es que no.

De una parte, el requisito de veracidad es más bien redundante. Como ha sugerido Ortí Vallejo la veracidad es algo que se presupone pues, en general, existe una interdicción de la falsedad en este ámbito ${ }^{56}$.

Por otra, como señala Gómez Segade, con cita a la Federal Trade Comisión, de lo que se trata es que la información sea "útil, utilizable y usada" 57 . Desde luego para satisfacer este objetivo es necesaria la veracidad, pero no es suficiente.

La información debe, además, ser comprensible ${ }^{58}$. En general, que la información sea comprensible significa que su contenido resulta intelectualmente accesible a un consumidor medio sin que deba realizar un esfuerzo intelectual extraordinario o requiere la asistencia de terceros o procurarse otra información adicional ${ }^{59}$.

En tercer lugar, aun cuando resulta necesario que la información sea suministrada en forma oportuna al consumidor, dicho requisito se subentendería si se exigiera que la información resultara útil para este.

Ahora bien, se gana en precisión si se vincula la regla del artículo 3 b) con la noción de "información básica comercial" contemplada en el artículo 1.3 de la ley no 19.496 . Mi sugerencia es que la regla general debe integrarse con la disciplina de la información básica comercial. Al hacerlo

tido, Ortí Vallejo (1992) 404, ha afirmado que: "En cuanto a la finalidad [del derecho de información del consumidor], es unánime la doctrina en considerar que el objetivo de la atribución del derecho de información del consumidor, no es otro que facilitar que el consentimiento que presta al contratar un producto o servicio haya sido formado clara y reflexivamente".

56 Ortí Vallejo (1992) 411. La interdicción de falsedad es más bien ubicua en el derecho comparado, incluso en un sistema refractario a la imposición de deberes precontractuales de información como el inglés, proscribe severamente la entrega de información falsa. Sobre este tema puede consultarse Allen, D. (1988). Misrepresentation, Londres: Sweet \& Maxwell, y Cartwright, J. (2007). Misrepresentation, Mistake and Non-Disclosure, Londres: Sweet and Maxwell.

57 Gómez Segade (1980) 148.

58 En este sentido, el artículo 2:206 de los Acquis Principles, bajo la rúbrica Clarity and form of information dispone en su número uno: "A duty to provide information imposed on a business is not fulfilled unless the information is clear and precise, and expressed in plain and intelligible language". Que es traducido en Arroyo i Amayuelas, E. (2008). "Los principios de Derecho contractual comunitario" en $A D C$, vol. 61, No1, p. 224 de la siguiente manera: "El deber de información impuesto al profesional no se entiende cumplido, salvo que la información sea clara y precisa y expresada en un lenguaje sencillo e inteligible".

59 Una idea semejante respecto de la transparencia de las condiciones generales en PerTíñez Vílchez, F. (2004). Las cláusulas abusivas por un defecto de transparencia, Cizur Menor (Navarra): Thomson Aranzadi, pp. 68-69. 
de esta manera, y prestando atención al artículo 32 de la ley ${ }^{60}$, se advierte que dicha información debe suministrarse "en idioma castellano, en términos comprensibles y legibles".

\section{(ii) El contenido de la información}

Una vez más, de lo que se trata es que la voluntad del consumidor se forme correctamente, es, entonces, en función de ese cometido que debe evaluarse la información cuyo suministro se impone al proveedor.

El artículo 3 b) indica que la información que debe proporcionarse es "sobre los bienes y servicios ofrecidos, su precio, condiciones de contratación y otras características relevantes de los mismos".

Se trata, como puede verse, de un alcance extremadamente amplio, y es correcto que así sea. No resulta posible enunciar taxativamente cuál sea la información que un consumidor promedio necesita para formar adecuadamente su voluntad, las peculiaridades del caso lo determinarán. No obstante lo anterior, resulta adecuado establecer ciertos mínimos que orienten al proveedor y a este respecto, la norma resulta extremadamente parca $^{61}$. En términos de técnica legislativa hubiese resultado preferible incorporar dentro de ese catálogo de información mínima alguna información que se encuentra dispersa en el articulado de la ley. Así, por ejemplo, sucede con la información, cuyo suministro impone el artículo 14 de la ley 19.496, respecto al hecho de que los productos se venden con alguna deficiencia, son usados, refaccionados o en cuya fabricación se hayan utilizado partes o piezas usadas. Igualmente es el caso de la información respecto del precio a que se refiere el artículo $30^{62}$.

(iii) Consecuencias del incumplimiento de los deberes precontractuales de información

Las consecuencias del incumplimiento de los deberes precontractuales de información pueden ser variadas. En primer lugar es posible $-\mathrm{y}$

60 La técnica legislativa de la ley 19.496 no es precisamente elogiable. La utilización de una técnica más depurada debería eliminar la "información básica comercial" e integrar su contenido en las reglas sobre contratación, rotulado y publicidad.

61 Por ejemplo no se alude a la individualización del proveedor.

62 El farragoso fraseo del artículo 30 podría reemplazarse por una fórmula más concisa como la del artículo 60.2.b) del Texto Refundido de la Ley General para la Defensa de los Consumidores y Usuarios y otras leyes complementarias español, según el cual se debe informar: "Precio completo, incluidos los impuestos, o presupuesto, en su caso. En toda información al consumidor sobre el precio de los bienes o servicios, incluida la publicidad, se informará del precio final completo, desglosando, en su caso, el importe de los incrementos o descuentos que sean de aplicación, de los gastos que se repercutan al consumidor y usuario y de los gastos adicionales por servicios accesorios, financiación u otras condiciones de pago similares". 
frecuente- la aplicación de sanciones de carácter infraccional, consistentes en multas ${ }^{63}$. En segundo lugar, en sede reparatoria, el artículo 3 e) establece, en lo que es de interés aquí:

"El derecho a la reparación e indemnización adecuada y oportuna de todos los dalos materiales y morales en caso de incumplimiento de cualquiera de las obligaciones contraídas por el proveedor...”.

Dos cuestiones resultan relevantes respecto del ejercicio de la acción de daños. La primera se refiere a la competencia del órgano jurisdiccional, la segunda al régimen de responsabilidad que disciplina el ejercicio de la acción. Con respecto a la competencia, el artículo $50 \mathrm{~A}$ dispone, en lo pertinente, que "Los jueces de policía local conocerán de todas las acciones que emanan de esta ley..." 64 . Esta regla de competencia absoluta, sin embargo, se altera en el caso de que la pretensión reparatoria sea canalizada a través de lo que la ley 19.496 denomina "Procedimiento Especial para Protección del Interés Colectivo o Difuso de los consumidores", en cuyo caso la competencia se desplaza hacia los tribunales ordinarios de justicia ${ }^{65}$.

En lo que se refiere al régimen de responsabilidad se trata, por cierto, de ilícitos precontractuales y, por lo mismo, a primera vista, resulta tentador afirmar la vigencia del estatuto de responsabilidad extracontractual contenido en los artículos 2.314 y siguientes del Código Civil. Esta pareciere ser la opinión dominante en la doctrina chilena ${ }^{66}$. Sin embargo, si se presta suficiente atención se advierte que esa opinión suele restringirse a un tipo de ilícito precontractual: la ruptura arbitraria de los tratos preliminares ${ }^{67}$. Este es un supuesto diverso: incumplimiento de deberes precontractuales de informar. En este supuesto, la respuesta a la cuestión acerca del régimen de responsabilidad, en definitiva, va a depender de dos circunstancias: (1) que el contrato se haya celebrado y (ii) la posibilidad

63 La regla supletoria -y, por lo tanto, general- en materia de multas se encuentra en el artículo 24, según el cual -en lo que aquí interesa-: "Las infracciones a lo dispuesto en esta ley serán sancionadas con multa de hasta 50 unidades tributarias, si no tuvieran señalada una sanción diferente".

64 Al respecto ver Cortez Matcovitch (2004) 37-66.

65 Es decir el Juzgado de Letras en lo Civil de la comuna o agrupación de comunas determinado según lo dispuesto en los artículos 134 y siguientes del Código Orgánico de Tribunales. Sobre el tema Cortez Matcovitch (2004) 67-139.

66 Ver supra nota 59.

67 En el ámbito chileno existe acuerdo respecto a que es el estatuto extracontractual en el caso de retiro arbitrario de las tratativas preliminares. Sobre esto puede consultarse Corral TALCIANI, H. (2003). Lecciones de responsabilidad civil extracontractual, Santiago: Editorial Jurídica de Chile; Domínguez Benavente, R. et al. (1996). "Comentarios de Jurisprudencia" en Revista de Derecho, Universidad de Concepción, No 199, pp. 179-183; y Meza Barros, R. (1980). Responsabilidad civil, Valparaíso: Edeval, p. 66; Barros Bourie (2006) 1004, Barrientos Zamorano (2008) 117-121, y Celedón Förster, R., y Silberman VeszpreMI, P. (2010). Responsabilidad precontractual por ruptura de negociaciones contractuales, Santiago: Editorial Jurídica de Chile, pp. 132-137. 
de vincular el incumplimiento del deber con un incumplimiento contractual. Si ambas circunstancias concurren entonces el ilícito precontractual puede ser absorbido por el régimen contractual ${ }^{68}$.

Junto a consecuencias de carácter infraccional y reparatorias, la omisión en la entrega de información o la entrega de información incorrecta por parte del proveedor podrían determinar -si se satisfacen los requisitos- supuestos de error, dolo o vicios redhibitorios ${ }^{69}$.

\section{CONCLUSIÓN}

El suministro de información como técnica de protección es un tema al cual la doctrina nacional ha prestado escasa atención, limitándose más bien a menciones aisladas o tratamientos fragmentarios. La importancia de esta técnica en el derecho comparado -particularmente en el derecho europeo- aconseja prestarle atención en el ámbito nacional.

68 La absorción de ilícitos precontractuales en la responsabilidad contractual es un tema que excede las posibilidades de estas páginas. Con todo, alguna noticia será conveniente. En términos muy generales, la absorción tendrá lugar en aquellos supuestos en los cuales se entregue información incorrecta sobre el bien o servicio y en aquellos casos en los cuales se omite información relevante. Si se suministra información incorrecta, por ejemplo, respecto de las características relevantes del bien o servicio, indudablemente se infringe un deber precontractual de información ex artículo 3 b), sin embargo, el remedio, según el artículo $21 \mathrm{~d}$ ) es de carácter contractual. Una cuestión similar plantea para el derecho español OrTí VALLEJo (1992) 420. Si se omite información relevante (por ejemplo los hoteles en que se alojará a los pasajeros de un exclusivo tour por Europa), se ha entendido que el contrato se integra según los requisitos de la buena fe objetiva, por lo tanto, aun cuando no se haya señalado en qué categoría de hoteles se alojarán los pasajeros, se entiende que estos deben ser acordes a las demás condiciones del paquete turístico. Véase Gómez Calle, E. (1998). El contrato de viaje combinado, Madrid: Civitas, p. 176. De manera que si se brinda un alojamiento en condiciones inferiores, aun cuando existe un ilícito precontractual -no haber suministrado información básica al consumidor- el consumidor puede alegar incumplimiento contractual y servirse, por lo tanto, de los remedios contractuales. Sobre el tema de la absorción de ilícitos precontractuales por el contrato puede consultarse De la Maza Gazmuri, I. (2007). "Deber de informar, dolo incidental e incumplimiento contractual. Nota a la STS de 11 de julio de 2007" en $A D C$ vol. 60 No 4, pp. 1861-1865. También resulta útil a estos efectos dar una mirada a los artículos 2:207 de los Principios Acquis, que establece la integración en el contrato de cierta información omitida y sus precedentes, esto es la CISG y de la Directiva 99/44 de ventas de bienes de consumo; al artículo 3.7 de los Principios UNIDROIT y al artículo 4:119 de los PECL, en la medida en que ambos preceptos regulan qué sucede cuando la misma hipótesis da lugar a causas de anulabilidad e incumplimiento de contrato.

69 Lo cual plantea un evidente problema de concurso de normas. En el ámbito nacional se ha ocupado del problema Caprile Biermann, B. (2008). "Las acciones del comprador insatisfecho: el cúmulo actual (ley de protección al consumidor, vicios redhibitorios, error sustancial, resolución por incumplimiento) y la tendencia al deber de conformidad en el derecho comparado", en Mantilla Espinoza, F., y Pizarro Wilson, C. (coords.): Estudios de Derecho Privado en homenaje a Christian Larroumet, Santiago: Fundación Fernando Fueyo Laneri y Universidad del Rosario, pp. 567-574, defendiendo la posibilidad de opción del consumidor entre normas de derecho común y reglas propias de la ley no 19.496. 
En este trabajo me ha interesado referirme a los aspectos más generales de dicha técnica, contextualizarla en el marco de la protección del consumidor, presentar sus ventajas y limitaciones, los distintos intereses que se procuran cautelar a través de ella y presentar la norma más estructural de la ley 19.496. Resta, aunque para trabajos siguientes, hacerse cargo de las reglas sobre publicidad y aquellas sobre deberes específicos de información.

\section{BiBLIOGRAFÍA}

- Aguilar Ruiz, L. (2001). La protección legal del consumidor de crédito, Valencia: Tirant lo Blanch.

- Allen, D. (1988). Misrepresentation, Londres: Sweet \& Maxwell, y Cartwright, J. (2007). Misrepresentation, Mistake and NonDisclosure, Londres: Sweet and Maxwell.

- Arroyo i Amayuelas, E. (2008). "Los principios de Derecho contractual comunitario" en $A D C$, vol. 61, No 1 .

- Bar-Gill, O. (2007). "Informing Consumers About Themselves", New York University Law and Economics Working Papers, p. 5. Disponible en http://lsr.nellco.org/cgi/viewcontent.cgi?article $=1115$ \&context =nyu/lewp [Fecha de visita: 10 de julio de 2008].

- Barrientos Zamorano, M. (2008). Daños y deberes en las tratativas preliminares de un contrato, Santiago: Legal Publishing.

- Barros Bourie, E. (2006). Tratado de responsabilidad extacontractual, Santiago: Editorial Jurídica de Chile Beluche Rincón, I. (2009). El derecho de desistimiento del consumidor, Valencia: Tirant lo Blanch.

- Bercovitz Rodríguez-Cano, A. (1987). "La protección de los consumidores, la Constitución española y el derecho mercantil", en Bercovitz Rodríguez Cano, Alberto / Bercovitz Rodríguez Cano, Rodrigo: Estudios jurídicos sobre la protección de los consumidores, Madrid: Tecnos.

- Calabresi, G. (1984). El costo de los accidentes, Barcelona: Editorial Ariel.

- Callejo Rodríguez, C. (2003). "El deber precontractual de información: del esquema tradicional del Código Civil al régimen del Derecho de Consumo", en Revista Jurídica del Notariado, No 47.

- Camerer, C. / Issacharoff, S. / Lowenstein, G. / Rubin. M. (2003). "Regulation for Conservatives: Behavioral Economics and the Case for "Asymetric Paternalism" en U. Pa. L. Rev., vol. 151.

- Caprile Biermann, B. (2008). "Las acciones del comprador insatisfecho: el cúmulo actual (ley de protección al consumidor, vicios redhibitorios, error sustancial, resolución por incumplimiento) y la tendencia al deber de conformidad en el derecho comparado", en Mantilla Espinoza, F., y Pizarro Wilson, C. (coords.): Estudios de De- 
recho Privado en homenaje a Christian Larroumet, Santiago: Fundación Fernando Fueyo Laneri y Universidad del Rosario, pp. 567-574.

- Celedón Förster, R., y Silberman Veszrpremi, P. (2010). Responsabilidad precontractual por ruptura de negociaciones contractuales, Santiago: Editorial Jurídica de Chile, pp. 132-137.

- Corral Talciani, H. (2003). Lecciones de responsabilidad civil extracontractual, Santiago: Editorial Jurídica de Chile.

- Cortez Matcovich, G. (2004). El nuevo procedimiento regulador en la ley $n^{\circ} 19.496$ sobre protección de los consumidores, Santiago: LexisNexis.

- De la maza Gazmuri, I. (2003). "Contratos por adhesión y cláusulas abusivas: ¿Por qué el Estado y no solamente el mercado?” en Revista Chilena de Derecho Privado, No 1, pp. 109-147.

- (2004). "El control de las cláusulas abusivas y la letra g)" en Revista Chilena de Derecho Privado, Fernando Fueyo Laneri No 3, 2004, pp. 35-68.

- (2005). "Los contratos por adhesión en plataformas electrónicas: una mirada al caso chileno" en SCRIPT-ed, vol. 2, no 3, disponible en http://www.law.ed.ac.uk/ahrb/script-ed/vol2-3/contratos.asp [Fecha de visita: 25 de julio de 2010]. (2006). "Justicia contractual, contratos de adhesión electrónicos y buena fe", en Corral Talciani, H., / Rodríguez Pinto, M.: Estudios de Derecho Civil, II Jornadas Nacionales de Derecho Civil, Olmué, Santiago: Editorial LexisNexis, pp. 571-592. (2007). "Deber de informar, dolo incidental e incumplimiento contractual. Nota a la STS de 11 de julio de 2007" en $A D C$ vol. 60 No 4, pp. 1861-1865.

(2009). "Ofertas sujetas a reserva: a propósito de los términos y condiciones en los contratos celebrados por medios electrónicos", en Revista de Derecho Universidad Austral de Chile, vol. 22 No 2, pp. 75-95

- (2010). Los limites del deber precontractual de información, Cizur Menor, Navarra: Thomson Reuters - Civitas.

- Díez-Picazo, L. (2010). "Los efectos de la imprevisión”, en prensa para Estudios de Derecho Civil VI.

- Díez-Picazo, L. (2007). Fundamentos del Derecho Civil Patrimonial, Introducción. Teoría del contrato, 6a ed., Cizur Menor (Navarra): Thomson Civitas.

- Díez-Picazo, L. (2008). Fundamentos de Derecho Civil Patrimonial, vol. II, Las relaciones obligatorias, 6a ed., Cizur Menor (Navarra): Thomson Civitas.

- Domínguez Benavente, R. et al. (1996). "Comentarios de Jurisprudencia” en Revista de Derecho, Universidad de Concepción, No 199, pp. 179-183. 
- Ebers, M. (2008). "Unfair Contracts Term Directive (93/13)", en Schulte-Nölke, H. / Twigg-Flesner, Ch. / Ebers, M. (edits.): EC Consumer Law Compendium. The Consumer Acquis and its transposition in the Member States, Munich: Sellier, pp. 245-250.

- Ehmann, H. / Sutschet, H. (2006). La reforma del BGB. Modernización del derecho alemán de obligaciones, trads. C. López Díaz y U. Salas de Sánchez, Bogotá: Universidad Externado de Colombia

- Eidenmüller, H. / Faust, F. / Grigoleit, H. / Jansen, N. / Wagner, G. / Zimmermann, R. (2008). "The Common Frame of Reference for European Private Law Policy Choices and Codification Problems" en Oxford Journal of Legal Studies, vol. 28-4

- García Vicente, JR. (2009). "Comentario Artículo 60", en Bercovitz Rodríguez-Cano, R. (coord.): Comentario del Texto Refundido de la Ley General para la Defensa de los Consumidores y Usuarios y otras leyes complementarias, Cizur Menor (Navarra): Aranzadi Thomson Reuters.

- Gómez Calle, E. (1998). El contrato de viaje combinado, Madrid: Civitas.

- Gómez Segade, J. (1980). "Notas sobre el derecho de información del consumidor" en RJC, No 3.

- Grisi, G. (1989). Voz: "Informazione (obblighi di)", en AA.VV: Enciclopedia Giuridica, vol. XVI, Roma: Istituto della Enciclopedia Italiana.

- Hadfield, G. / Howse, R. / Trebilcock, M. (1998). "InformationBased Principles for Rethinking Consumer Protection Policy", en Journal of Consumer Policy, vol. 28.

- Hanson, J. / Kysar, D. (1999). “Taking Behaviorism Seriously: Some evidence of Market Manipulation”, en Harv. L. Rev., vol. 112.

- Hillman, R. y Rachlinski, J. (2002). "Standard-Form Contracting in the Electronic Age”, en N.Y.U. L. Rev., vol. 77, pp. 429-456.

- Holtug, N. / Lippert-Rasmussen (edits.) (2007). Egalitarianism. New Essays on the Nature and Value of Equality, Oxford: Clarendon Press.

- Howells, G. (2005). "The Potential and Limits of Consumer Empowerment by Information", en Journal of Law and Society, vol. 32, pp. 352-356.

- Jolls, C./ Sunstein, C. / Thaller, R. (2000). "A Behavioral Approach to Law and Economics", en Sunstein, C. (ed): Behavioral Law \& Economics, Nueva York: Cambridge University Press.

- Korobkin, R. (2003). "Bounded Rationality, Standard Form Contracts, and Unconscionability" en U. Chi. L. Rev., vol. 70, pp. 12031295 .

- Larroumet, Ch. (2007). Droit civil, t. III, $1^{\text {a }}$ parte, Les obligations. Le contrat, 6a ed., París: Economica Malaurie, Ph. / Aynès, 
L. / Stoffel-Munck, Ph. (2003). Les obligations, $3^{\text {a }}$ ed., París: Defrénois.

- Martínez de Aguirre, C., et al. (2008). Curso de Derecho Civil, vol. II, Derecho de obligaciones, $2^{a}$ ed., Madrid: Colex.

- Martínez de Aguirre y Aldaz, C. (1994). "Trascendencia del principio de protección a los consumidores en el derecho de obligaciones" en $A D C$, Vol. 47 No 1.

- Meza Barros, R. (1980). Responsabilidad civil, Valparaíso: Edeval.

- Moreno-Luque Casariego, C. (2007). "Protección previa a la contratación de bienes y servicios”, en León Arce, A. (dir.): Derechos de los consumidores y usuarios, $2^{\mathrm{a}}$ ed., Valencia: Tirant lo Blanch, Valencia.

- Navarro Munuera, A. (1992). "Comentario artículo 3", en Bercovitz Rodríguez-Cano, R. y Salas Hernández, J.: Comentarios a la Ley general para la defensa de los consumidores y usuarios, Madrid: Civitas, p. 90.

- Ortí Vallejo, A. (1992). "Comentario artículo 13”, en Bercovitz, Rodríguez-Cano, R. I Salas Hernández, J.: Comentarios a la Ley General para la Defensa de los Consumidores y Usuarios, Madrid: Civitas.

- Palacios González, M. (2003). "El deber de información en los contratos con consumidores", en Espiau Espiau, S. / Vaquer Aloy, A., (edits.): Bases de un derecho contractual europeo, Valencia: Tirant lo Blanch, pp. 89-96.

- Pascuau Liaño, M. (1992). "Comentario artículo 8”, en Bercovitz Rodríguez-Cano, R. y Salas Hernández, J.: Comentarios a la Ley general para la defensa de los consumidores y usuarios, Madrid: Civitas

- Peguera Poch, M. (2008). "En el menú 'opciones', elija 'deshacer': el derecho a desistir del contrato electrónico", en Cotino Hueso, L. (Coord.): Consumidores y usuarios ante las nuevas tecnologias, Valencia, Tirant lo Banch.

- Peñailillo Arévalo, D. (2003). Obligaciones. Teoría general y clasificaciones. La resolución por incumplimiento, Santiago: Editorial Jurídica de Chile

- Pérez García, P. A. (1990). La información en la contratación privada. Entorno al deber de informar en la Ley General para la defensa de los consumidores y usuarios, Madrid: Instituto Nacional de Consumo.

- Pérez Luño, E. (2005). Dimensiones de la igualdad, Madrid: Dykinson

- Pertíñez Vílchez, F. (2004). Las cláusulas abusivas por un defecto de transparencia, Cizur Menor (Navarra): Thomson Aranzadi.

- Pietrobon, V. (1971). El error en la doctrina del negocio jurídico, trad. M. Alonso Pérez, Madrid: Editorial Revista de Derecho Privado.

- Pizarro Wilson, C. (2005). "El incumplimiento licito del contrato por el consumidor: "El derecho de retracto" en Actualidad Juridica, Año VI, No. 11. 
- Posner, R. (1998). "Rational Choice, Behavioral Economics, and the Law", en Stanford Law Review, vol. 50, pp. 1551-1575.

- Reyes López, M.a / Puertes Martí, A. / Estruch Estruch, J. I Montés Rodríguez, P. (1995). Jurisprudencia en materia de protección de consumidores y usuarios, Valencia: Editorial Práctica de Derecho Riesenhuber, K. (2001). "Party Autonomy and Information in the Sales Directive", en Grundmann, et al:: Party Autonomy and the Role of Information in the Internal Market, Berlín: De Gruyter, pp. 348-370.

- Schulte-Nölke, H. y Meyer-Schwickerath, L. (2008). "Price Indication Directive (98/6)", en Schulte-Nölke, H., Twigg-Flesner, Ch. / Ebers, M. (edits.), EC Consumer Law Compendium. The Consumer Acquis and its transposition in the Member States, Munich: Sellier.

- Schulte-Nölke, H. / Meyer-Schwickerath, L. (2008). "Package Travel Directive (90/314)" en Schulte-Nölke, H. / Twigg-Flesner, Ch. I Ebers, M. (edits.): EC Consumer Law Compendium. The Consumer Acquis and its transposition in the Member States, Munich: Sellier, pp. 133-158.

- Schulte-Nölke, H. / Börger, A. (2008). "Distance Selling Directive (97/7)", en Schulte-Nölke, H. / Twigg-Flesner, Ch. / Ebers, M. (edits.): EC Consumer Law Compendium. The Consumer Acquis and its transposition in the Member States, Munich: Sellier, pp. 327-340.

- Slawson, D. (1996). Binding Promises: the Late 20th century reformation of contract law, New Jersey: Princeton University Press, p. 23.

- Tapia Rodríguez, M. / Valdivia Olivares, J.M. (2002). Contratos por adhesión. Ley No 19.496, Santiago: Editorial Jurídica de Chile.

- Terré F. / Simler, Ph. / Lequette, Y. (1996). Droit civil. Les obligations, 6a ed., París: Dalloz

- Treitel (1999). The Law of Contract, 11a ed., Londres: Sweet \& Maxwell.

- Vigneron-Maggio-Apr S. (2006). L'information des consommateurs en droit européen et en droit suisse de la consommation, Ginebra: Bruylant Schulthess.

- Weatherhill, S. (2001). "Justifying Limits to Party Autonomy in the Internal Market", en Grundmann, et al:: Party Autonomy and the Role of Information in the Internal Market, Berlín: De Gruyter.

- Weatherill, S. (2005). EU Consumer Law and Policy, Cheltenham: Edward Elgar Publishing Limited.

- Wilhelmsson, T. / Twigg-Flesner, Ch. (2006). "Pre-contractual information duties in the acquis communautaire" en European Review of Contract Law, No 4, vol. 2, pp. 456- 457.

- Zimmermann, R. (2000). Estudios de Derecho Privado Europeo, trad. A. Vaquer Aloy, Madrid: Civitas. 